\title{
Ailstortias
}

\section{O liberalismo do Primeiro Reinado: uma análise das ideias liberais de João Maria da}

\section{Costa (1826)}

DOI: $10.26512 /$ emtempos.v1i33.23553

Arthur Ferreira Reis ${ }^{1}$

\section{Resumo:}

O processo de independência do Brasil foi marcado por um intenso alargamento dos espaços públicos. Entusiasmados pela recém conquistada liberdade de imprensa e conscientes do momento singular na construção da nação, diversos redatores iniciaram sua participação na cena pública através de periódicos e panfletos. Nesse contexto, formou-se uma elite intelectual brasileira que em seus escritos construiu linguagens políticas, modificou o significado de conceitos e se mobilizou para defender os mais distintos projetos políticos. Incluído nesse processo está o redator João Maria da Costa e seu jornal Atalaia da Liberdade. Publicado em um momento em que o governo de D. Pedro I estava em seu ápice, se destacando na repressão à imprensa e aos opositores políticos, a derrota da Confederação do Equador e o fechamento da Assembleia Constituinte, João Maria foi uma das principais vozes de oposição ao ministério do Imperador. Defendendo o exercício pleno da liberdade pelos cidadãos brasileiros, a abolição imediata da escravidão e até mesmo o início de um governo federalista/republicano no Brasil, João Maria atraiu para si a ira dos governistas e chegou a ser agredido fisicamente. Essa pesquisa busca, através do periódico Atalaia da Liberdade, resgatar o discurso liberal de João Maria no Primeiro Reinado.

Palavras-chave: Imprensa; Primeiro Reinado; Intelectuais; Periódicos.

\begin{abstract}
:
The process of Brazil's independence was marked by an intense expansion of public spaces. Enthusiastic about the newly conquered freedom of the press and aware of the unique moment in the construction of the nation, several writers began their participation in the public scene through periodicals and pamphlets. In this context, Brazilian intellectual elite was formed who in his writings constructed political languages, modified the meaning of concepts and mobilized to defend the most different political projects. Included in this process is the writer João Maria da Costa and his newspaper Atalaia da Liberdade. Published at a time when D. Pedro I's government was at its peak, standing out in the repression of the press and political opponents, the defeat of the Confederation of Ecuador and the closing of the Constituent Assembly, João Maria was one of the main voices of opposition to the Emperor's ministry. Defending the full exercise of freedom by Brazilian citizens, the immediate abolition of slavery, and even the beginning of a federalist/republican government in Brazil, João Maria attracted the ire of the governors and was physically threatened. This research seeks, through the newspaper Atalaia da Liberdade, to understand the liberal discourse of John Mary in the First Kingdom Keywords: Press; First Reign; Intellectuals; Newspapers.
\end{abstract}

\section{O liberalismo brasileiro}

O furacão político que transformou o Brasil nos anos tem aumentou o interesse da população sobre o que tem ocorrido no cenário político nacional. Assuntos como inflação, dívida pública, carga tributária e outros que normalmente não eram comuns em uma conversa trivial, tem se tornado habitual em encontros familiares, de amigos e, principalmente, na

\footnotetext{
${ }^{1}$ Mestre em História pela Universidade Federal do Espírito Santo.
} 
internet. Nessa popularização da política, alguns termos da ciência política têm se disseminado na sociedade, e mesmo que de forma dispersa e descuidada cientificamente, conceitos como esquerda, direita, liberalismo, comunismo, fascismo e socialismo estão na "boca do povo".

Destacamos, para os fins desse trabalho, o conceito de liberalismo. Conhecido pelo público em geral em sua forma econômica, o liberalismo tem ganhado adeptos por todo o Brasil. Exemplo disso é a grande quantidade de pré-candidatos à presidente que se assumiram no ano de 2018 como defensores de bandeiras liberais ${ }^{2}$. Além desses políticos, uma grande operação social, seja na internet ou em movimentos sociais, tem buscado defender e divulgar a bandeira do liberalismo como algo novo, inédito no Brasil, uma solução capaz de resolver o atraso econômico, os problemas científicos e a questão da segurança pública ${ }^{3}$. Alegando defender a liberdade pessoal, os liberais cada vez mais ganham espaço em um país marcado por um Estado inchado economicamente e que se pretende legislador de questões sociais, mas que em seus aspectos básicos, como saúde, educação e segurança, tem deixado muito a desejar.

O difuso pensamento liberal da atualidade merece olhar mais atento. Em detrimento de sua pluralidade de ideias e o descompromisso científico de muitos de seus representantes, os liberais conseguem capilaridade entre a população jovem, algo que os tradicionais partidos de “esquerda” não têm conseguido ${ }^{4}$. Alguns discursos, mesmo aqueles mais superficiais, são considerados por parte da população como a solução para os problemas nacionais, o que tem sido demonstrado no fantasioso debate político que se dá na opinião popular expressa em redes sociais, jornais e blogs - o que, vale destacar, não tem sido uma particularidade dos liberais.

Tendo em vista essa problemática atual e analisando alguns discursos dos "liberais" brasileiros do século XXI, pode-se perceber que em detrimento da confusão conceitual e da obscura ligação entre eles, os liberais carregam consigo um conceito central, a liberdade (Cf. PEIXOTO, 2001). Seja qual for sua proposta ou ideia social e econômica, seja o que queira defender ou atacar, a liberdade é o símbolo dos liberais.

Se levarmos em conta que o conceito de liberdade é um dos mais plurais, a rapidez dos liberais brasileiros em citar a liberdade como mote político nos lembrou um dos períodos em

\footnotetext{
2 Dentre os candidatos que têm destacado uma política econômica, podemos destacar Henrique Meirelles, Jair Bolsonaro, Geraldo Alckmin e João Amoêdo.

${ }^{3}$ Podemos destacar alguns sites/institutos que tem grande apelo online como o Instituto Milllenium, os Institutos Liberais espalhados pelo brasil, o Mises Brasil e o Students For Liberty.

${ }^{4}$ Um bom exemplo desse sucesso do liberalismo é o grande número de canais no youtube que se autodenominam liberais. Páginas como "Mamãefalei”, “Ideias Radicais” e "MBL - Movimento Brasil Livre” destacam-se entre as mais vistas na rede social de vídeos quando o assunto é política ou economia.
} 
que ela também era comum no Brasil, o Primeiro Reinado. Em um momento no qual o Brasil acabava de conquistar sua independência, a liberdade era quase um atestado de patriotismo, pois ninguém, independentemente de sua posição política, seria capaz de ir contra ela.

Similar ao que acontece hoje, todos os homens do Primeiro Reinado que defendiam a liberdade se intitulavam liberais. É quase unanimidade na historiografia do Primeiro Reinado que inexistia um político ou um jornalista que se dissesse defensor do absolutismo ou contrário à liberdade (Cf. NEVES, 2003). O que variava entre cada era o que entendia como liberdade, quem poderia ser livre ou qual o limite da liberdade.

Entretanto, como se falar em liberdade em um país no qual a base social era escrava? Esse era um dos dilemas que os liberais do Primeiro Reinado tiveram que resolver (Cf. SCHWARZ, 2001). Se para uns, os escravos eram uma propriedade e como tal ir contra a instituição da escravidão seria um atentado contra a propriedade individual, para outros, a escravidão devia ser abolida gradualmente. Como conceito difuso, a liberdade se impunha como um ideal, mas não igualmente para todos.

Tendo em vista essa problemática a respeito da liberdade e levando em conta a importância do tema para o debate político e social que se impõe atualmente, buscamos um jornal do Primeiro Reinado que se relacionasse com os pontos fundamentais das ideias liberais do período e trouxesse contribuições para pensarmos o liberalismo atual. Na abundância de periódicos que preenche o Primeiro Reinado, selecionamos o jornal Atalaia da Liberdade de João Maria da Costa.

João Maria da Costa foi um português nascido na Ilha da Madeira que se radicou no Brasil entre os anos de 1815 e 1820. Passou por Montevidéu sendo um dos grandes negociantes e, ao se iniciar os conflitos entre a Cisplatina e o Brasil, mudou-se para o Rio de Janeiro, dizendo ter se tornado brasileiro em amor ao país que o adotara (ATALAIA DA LIBERDADE, 1826: $3)^{5}$. Infelizmente grande parte de sua vida é desconhecida, mas sabemos que após a publicação da Atalaia em 1826, passou pelos Estados Unidos de onde voltou em 1828 para redigir o jornal governista Gazeta do Rio de Janeiro. Após desavenças com a cúpula ministerial novamente se exiliou do Brasil para a Inglaterra, quando perdemos o rastro de sua vida.

O periódico aqui analisado, Atalaia da Liberdade, foi escrito logo quando ele chegou no Rio de Janeiro. Além de expor suas ideias sobre a política nacional e seu projeto de nação,

\footnotetext{
${ }^{5}$ Para tornar mais fluído o texto, vamos atualizar a escrita do periódico e abreviar, nas referências no corpo do texto, Atalaia da Liberdade para A.L.
} 
João Maria também tinha como objetivo discutir as notícias sobre as agitações na então província da Cisplatina. O jornal continha 4 páginas e custava 80 réis por edição ou 4 mil réis por trimestre e circulava todas as quarta-feira, quinta-feira e sexta-feira. Teve um total de 13 edições, todas usadas nessa pesquisa. Nosso objetivo nesse trabalho, tendo como perspectiva metodológica o contextualismo linguístico (Cf. POCOCK, 2003), é compreender as características do pensamento político de João Maria da Costa tendo em mente a sua relação com as ideias que circulavam no círculo intelectual brasileiro.

\section{O liberalismo e a opinião pública no Brasil}

O pensamento liberal no Brasil teve seu início com a chegada das ideias iluministas no século XVIII com alguns estudantes de Coimbra e outras universidades europeias (Cf. CARVALHO, 1980), e se fortaleceu durante o processo de independência. A oposição entre os grupos liberais coimbrão e brasiliense (Cf. NEVES, 2003), causou, durante os anos de 1821 e 1822, um desenvolvimento do pensamento liberal e o consequente florescimento de vários projetos políticos ${ }^{6}$. Entre eles, muitos dos quais ainda não explorados pela historiografia, destacaram-se quatro: o projeto liberal afiançado na pessoa do Imperador, no qual apenas um governo central forte seria capaz de manter as liberdades conquistadas com a Constituição e a Independência (Cf. REIS, 2016); um projeto federalista, que defendia a província como espaço de exercício da liberdade (Cf. DOLHNIKOFF, 2005); o projeto republicano (Cf. FONSECA, 2005), que ligava o Brasil a uma tradição americana de governos republicanos, única forma de se evitar o despotismo e garantir o exercício da liberdade individual; e, por último, um projeto moderado (Cf. BASILE, 2004), que via no poder legislativo federal uma maneira de evitar tanto o despotismo por parte do Imperador, quanto a anarquia proveniente do caudilhismo provincial. Todavia, a diversidades desses projetos se dava dentro de uma matriz liberal que se erigiu após a Revolução Francesa, baseada na liberdade individual, sistema constitucional, separação de poderes, proteção à propriedade privada e oposição aos regimes absolutistas.

\footnotetext{
${ }^{6} \mathrm{O}$ pensamento liberal brasileiro do período imperial conheceu variáveis de acordo com os acontecimentos. Grosso modo, no processo de independência o pensamento liberal tratou como prioridade elaboração de uma constituição e seu fortalecimento, ao passo que no fim do Primeiro Reinado e inicio da Regência os liberais priorizaram o fortalecimento das instituições, a consolidação das instituições e a descentralização administrativa. O conceito de liberdade esteve presente em todos esses momentos sendo entendida de forma distinta, mas com características afins. Todavia, grande parte dos liberais brasileiros do período imperial (com exceção dos radicais) foram afeitos à uma caracterização mais moderada do pensamento liberal, tratando a liberdade ideal como a "bem entendida liberdade” ou “o justo meio”. Cf: MARSON, Izabel Andrade; OLIVEIRA, Cecília Helena Lorenzoni de S. (Orgs.). Monarquia, liberalismo e negócios no Brasil (1780-1860). São Paulo: EDUSP, 2013; VAINFAS, Ronaldo. Dicionário do Brasil Imperial. São Paulo: Companhia das Letras, 2009.
} 
A criação desses projetos ocorreu através, mas não unicamente, de uma elite intelectual e política que desabrochou a partir de 1821. Se por um lado, a elite econômica brasileira percebeu no retorno de D. João VI para Portugal, a convocação das eleições dos deputados brasileiros para as Cortes de Lisboa e a liberdade de imprensa, a oportunidade de se apresentar como líder da opinião pública e dilatar seu poder por além dos círculos privados. Por outro, aqueles já conhecidos pelos dirigentes estatais, tiveram que se mostrar às massas como representantes de suas vontades. Para conseguir isso, a opinião pública revelou-se como espaço privilegiado de debate, permitindo que atores que até então não tinham notoriedade nos espaços públicos se aproveitassem da conjuntura e adquirissem renome.

No contexto da independência destacaram-se as figuras de José Bonifácio e Gonçalves Ledo. Líderes dos dois grupos mais prestigiados da cena pública brasileira, lançaram mão de manifestos, periódicos, discursos e de seus contatos na corte fluminense para garantir que seus projetos saíssem vencedores no embate. Pouco a pouco os espaços públicos brasileiros foram sendo preenchidos a partir do processo de independência por diversos jornais e panfletos que se misturavam com as manifestações populares, discursos aclamados nas ruas, levantes militares, sociedades secretas e espaços de sociabilidade. Os espaços públicos se emancipavam e ganhavam importância na sociedade, se transformando, progressivamente, em um intermediador entre a sociedade e o poder do Estado (Cf. HABERMAS, 2003).

Com a independência e as consequentes disputas políticas, grupos diferentes passaram a rivalizar pelo predomínio no palácio e nos espaços públicos. Com a dissolução da constituinte em 1823 e a repressão à Confederação do Equador em 1824, o governo de D. Pedro I passou por um período de tranquilidade e ausência de oposição. Com isso houve um avanço das ideias centralizadoras alçadas pelo grupo político palaciano, também conhecido como áulico, que através de jornais e liturgias públicas dominaram a cena pública fluminense por quase dois anos.

Em 1826 com a proximidade da reabertura do parlamento e a agitação que prenunciava a Guerra da Cisplatina alguns panfletos e jornais começaram a aparecer no Rio de Janeiro. Discussões que até então pareciam ter desaparecido, como a soberania do poder legislativo sobre o executivo e as críticas à excessiva centralização do governo no Rio de Janeiro, retornaram. Nesse momento surgiu o periódico Atalaia da Liberdade. Liberal confesso, se relacionava com o grupo oposicionista que ascendeu no ano de 1826. Junto com outro jornalista, o francês Pierre Chapuis e seu periódico O Verdadeiro Liberal, criticavam as atitudes 
ministeriais e lutavam por uma mudança na política brasileira (Cf. REIS, 2016). Tendo em vista esse contexto, passemos às ideias de João Maria.

\section{O liberalismo de João Maria}

As ideias de João Maria serão analisadas do ponto de vista econômico, político e social. A pouca quantidade de jornais, quando comparado com outros periódicos mais influentes do período, nos deixa com algumas questões em aberto sobre o pensamento do jornalista português, mas as treze edições disponíveis são o suficiente para conhecermos o que João Maria projetava como ideal para uma sociedade.

Do ponto de vista econômico, João Maria se colocava como um defensor do livrecomércio. Bandeira tradicional dos liberais (Cf. SMITH, 1996), o livre-comércio, para o jornalista, seria uma condição para o desenvolvimento social dos homens, além dos inegáveis benefícios econômicos. O comércio “é a comunicação reciproca das coisas necessárias ou agradáveis a vida”, e "sua circulação livre em todos os países é um método infalível de multiplica-la”. Isso se dá porque em um único “país em regra não abunda em todas as [ilegível] de produções: a diversidade de clima, e terrenos obsta à uniformidade de produtos: eis aí os homens obrigados à troca de seus gêneros para reunir diversas produções” (A.L., 1826: 11).

O comércio, além de multiplicar as riquezas, também é o responsável por unir os povos distantes através de uma grande rede de comunicação comercial, mesmo àqueles que "a natureza separou por mares derramados, e desertos”. Isso se dá porque foi graças à busca de mercado para vender seus produtos que "o homem atravessou os mares, flanqueou as montanhas, avassalou os rios, construiu canais, abriu estradas”. A atividade comercial é o “sangue que vivifica o corpo social”, a responsável por “civilizar os povos, e multiplica os meios de subsistência, bem como os objetos de comodidade, excitando por toda a parte a indústria dos homens”. Enfim, o comércio e a circulação de bens tem como “objeto principal (...) manter a paz dos Povos” (A.L., 1826: 11).

Dessa forma, o comércio tornava-se essencial não só para aumentar a riqueza de um país, mas também para criar meios de comunicação entre os povos e melhorar sua convivência. O discurso econômico misturava-se com questões políticas e sociais em um anseio pelo livremercado que vai permear grande parte da elite imperial, sem nunca ser plenamente realizado (Reis, Entre Smith e Quesnay: o debate econômico entre Plancher e Chapuis no Rio de Janeiro (1826), 2015). 
Do ponto de vista político, João Maria fazia ampla defesa do governo constitucional. Tinha como ideais “Nação, Justiça, e Liberdade” (A.L., 1826: 3) que estariam garantidos “por uma boa Constituição” (A.L., 1826: 6). Para o autor, existiam três tipos de governos: o absoluto, o constitucional e o republicano. O primeiro, em sua visão, é o governo de um só, que irremediavelmente se arrasta para o despotismo. Já o republicano sempre desagua na desordem, pois arrasta “grandes estorvos, resoluções tardias” e é de “execução difícil”, graças à grande quantidade de “partidos, facções” que causam a “dissolução do vínculo social” (A.L., 1826: 12).

Para evitar esses dois tipos de governo e as desvantagens que deles acarretam, era necessário o fortalecimento do governo constitucional, que é “o resultado das combinações mais profundas da sabedoria e da existência”. Esse desfecho positivo do governo constitucional podia ser percebido através da história da humanidade, pois

Os homens uniram-se em sociedade para serem felizes, gozando liberdade, propriedade, segurança, e os prazeres, que nascem destes bens. Estabeleceram-se, e epitetaram-se diversas formas na organização social: os inconvenientes de todos deram nascimento ao governo constitucional (A.L., 1826: 12).

Dessa forma, apenas um "governo guiado por uma boa Constituição, e com vigilantes e aturados zeladores de sua observância pode ser durável, e venturoso” (A.L., 1826: 6). Dito isso, os brasileiros deveriam lutar pelo fortalecimento de dispositivos liberais e constitucionais no Brasil, tais como a "divisão dos poderes, a responsabilidade dos Ministros, a vigilância sobre todos os empregados” (A.L., 1826: 12).

Outra pauta liberal que João Maria expunha e que misturava aspectos políticos e sociais era o individualismo. Para ele, cada indivíduo tinha suas próprias características, o que tornava errado a criação de leis gerais para os diferentes tipos de pessoas e classes. A sociedade era composta por classes diversas e cada cidadão, dentro dessas classes, tem seus interesses particulares. É, “portanto, indispensavelmente necessário considerar cada classe e seu interesse com o respeito devido aos cidadãos que a compõe” (A.L., 1826: Extraordinário). Sendo diferentes, seria impossível que as pessoas agissem de forma semelhante, pois "homem no estado moral, e político, é mesmo o homem físico, não é mais, que um mero jogo das circunstâncias, que o acompanham, e o conduzem”. Concluía afirmando que “cada qual na sociedade tem seus diferentes interesses, muitas vezes, o que faz bem a uns, é prejudicial aos outros” (A.L., 1826: 3). 
Sobre seu pensamento social, destacamos primeiramente sua defesa liberdade de religião. Para ele era necessário que o Estado respeitasse e tolerasse a fé e os cultos, pois a religião era uma escolha privada do indivíduo (A.L., 1826: Extraordinário). O Estado devia "ser tolerante” com as demais religiões e respeitar a opinião do indivíduo (A.L., 1826: Extraordinário).

Mas o que coloca João Maria em evidência entre os intelectuais brasileiros do Primeiro Reinado é sua defesa pela abolição da escravidão. Diferenciando-se das opiniões correntes sobre o tema, defendia a abolição imediata e acusava os traficantes ou compradores de escravos de estarem patrocinando um comércio imoral e irreligioso.

Para ele, “uma nação de escravos, sempre é fraca, logo a abolição da escravatura é um baluarte da liberdade brasileira”. De nada o gênero humano poderia colher “desses horrores”, pois a “escravidão não é em si mesmo bom para nada”. Ela “degrada, e injuria a espécie humana; e a vista do qual o coração do ente social naturalmente se revolta, não traz utilidade alguma à Nação, que o consente e promove” (A.L., 1826: 2).

Pensando individualmente, ela é ruim ao senhor "porque este contrai entre os seus escravos toda a sorte de maus hábitos, e acostuma-se ao abandono de todas as virtudes morais. Ele se faz altivo, colérico, obstinado, vingativo, voluptuoso e cruel”. É ruim ao escravo não apenas porque ele está privado de sua liberdade, mas também “porque este nada pode fazer por princípios virtuosos” (A.L., 1826: 8).

Além da escravidão representar uma barreira ao desenvolvimento moral e social do Brasil, ela também era imoral em si própria. Os escravos, para João Maria, eram “nossos semelhantes”. Enfatizava com escândalo a contradição entre o cristianismo e a escravidão, lembrando que a própria igreja apoiava esse tipo de prática que diminuía seres humanos à condição de "brutos” (A.L., 1826: 10). Denunciava também os maus tratos aos africanos no transporte para o Brasil através de relatos. Em um deles ilustrou a triste situação dos navios negreiros, mostrando que além de ir contra a moral cristã, a escravidão era, em si mesma, um assassinato em massa (A.L., 1826: 11).

Por esses motivos, advogava pelo fim imediato da escravidão. Dizia que devíamos deixar a Deus “formar cada um para si os seus planos de fortuna”. Apenas ele poderia "alterar a sorte de suas criaturas” (A.L., 1826: 10). Também arrogava pelas leis naturais que deviam ser respeitadas “em qualquer tempo, em qualquer lugar, e em qualquer povo”. Dentre elas, e a principal, seria a liberdade individual, afirmando com base nisso que "os homens não tem o 
direito de traficar em indivíduos da sua mesma espécie: pois que os homens, e a sua liberdade não são gênero de compra e venda” (A.L., 1826: 10).

Por fim, João Maria também arrogava por uma igualdade perante a lei. Todos deviam ter "iguais direitos". Para ele o que era necessário numa boa sociedade liberal era uma “igualdade de direitos, e não igualdade de circunstâncias”. Já que buscar uma igualdade absoluta entre todos seria impossível diante das individualidades de cada um, era necessário garantir ao homem a capacidade de "adquirir, conservar, usar e dispor, ou alienar qualquer cousa”, deixando a cada qual, segundo sua capacidade, a possibilidade viver com liberdade (A.L., 1826: 4).

Mas no que constituía a liberdade para João Maria? Ele mesmo alertava que é necessário compreender do que se trata essa liberdade, pois na América Hispânica “os Republicanos apregoando a liberdade e igualdade, e o Povo, que sem saber o que era igualdade, e liberdade, desatou-se todo, e fez aparecer as cenas pavorosas, que ainda hoje horrorizam” (A.L., 1826: 4).

Em sua visão, a liberdade não era absoluta, porque mesmo Adão que viveu sozinho na terra tinha obrigações com Deus. Em sua interpretação, ao entrar em sociedade o homem forma diversas relações com outros homens, formando obrigações e compromissos com seus iguais, o que diminui sua liberdade. Logo, “os deveres estão na razão direta das relações; e a liberdade está na razão inversa dos deveres, e por consequências das relações, das obrigações, e das leis”. Com isso, a liberdade absoluta é uma quimera (A.L., 1826: 4).

\section{Notas finais}

Como pudemos ver, o pensamento político e social de João Maria se aproximava tanto das ideias liberais de seu tempo, quanto do que atualmente os liberais dizem advogar. Livrecomércio, liberdade individual, igualdade de direitos e individualismo eram bandeiras que já no início do século XIX eram defendidas com afinco por grande parte da elite intelectual e política brasileira. Mesmo assim, essas propostas não foram postas em prática de forma inequívoca e duradoura.

O que diferencia e o que chama atenção em João Maria é sua opinião sobre a escravidão. Seus relatos sobre a forma de transporte de escravos e as acusações de maus tratos buscavam criar entre os brasileiros uma "empatia imaginada” (Cf. HUNT, 2009), principalmente quando apelava para questões morais e religiosas. Para ele não bastava uma abolição gradual, como era 
defendida por grande parte da elite intelectual (Cf. YOUSSEF, 2011), era necessária uma abolição imediata.

Além da vontade de ver a escravidão finalizada imediatamente, João Maria também tinha um aspecto singular quanto aos motivos por trás desse desejo. Grande parte da elite acusava a escravidão de prejudicar o desenvolvimento moral e social dos brancos (Cf. PRADO, 2001), de prejudicar economicamente o Brasil (Cf. ROCHA, 2000) ou temiam uma revolta escrava (Cf. CARVALHO, 1998). João Maria era contra ela por considerá-la imoral. Os escravos eram nossos semelhantes, um ser humano como qualquer outro e, como tal, tinha direitos naturais imutáveis. A base do pensamento liberal impunha-se até aos escravos, eles deviam ter liberdade. Os argumentos econômicos e políticos davam lugar ao argumento moral que tinha o escravo africano como centro da preocupação. Dessa forma, não é exagerado dizer que João Maria tinha ideias à frente de seu tempo ${ }^{7}$, o que o caracteriza como um liberal radical.

Em relação ao nosso liberalismo atual, podemos perceber que várias pautas de João Maria persistem. Entretanto, no que pese à questão social, achamos que falta aos nossos liberais um olhar mais cuidadoso. A pauta liberal, como pudemos ver nos discursos de João Maria, não se preocupava apenas com questões econômicas e políticas. Livre-comércio e liberdade individual sim, mas um Estado mais justo e garantidor de direitos iguais. Lembramos que no século XIX tivemos até mesmo uma proposta de “reforma agrária” (Cf. BASILE, 2004) feita por liberais.

Distante dessa preocupação social, o projeto liberal do século XXI parece não compreender que desenvolvimento econômico e social andam de mãos dadas. Torna-se imprescindível que o projeto liberal se expanda para além dos círculos econômicos e seja capaz de fazer com que os anseios financeiros vão de encontro com a promoção do desenvolvimento social e a diminuição das desigualdades, bandeira de muitos dos seus predecessores (Cf. SMITH, 1996).

\section{REFERÊNCIAS BIBLIOGRÁFICAS}

BASILE, M. O. (2004). O Império em construção: projetos de Brasil e ação política na Corte Regencial. Tese de Doutorado em História Social. Rio de Janeiro: I.F.C.S. - UFRJ.

\footnotetext{
${ }^{7}$ Segundo Marcello Basile, nem mesmo os liberais exaltados tinham concepção uniforme sobre o assunto. Cf. BASILE, Marcello Otávio Neri de Campos Basile. Anarquistas, Rusguentos e Demagogos: os liberais exaltados e a formação da esfera pública na corte imperial (1829-1834). 2000. 303 f. Dissertação (Mestrado em História Social) - Universidade Federal do Rio de Janeiro, Rio de Janeiro, 2000, p.86.
} 
CARVALHO, J. M. (1980). A Construção da Ordem. Rio de Janeiro: Editora da UFRJ.

CARVALHO, J. M. (1998). Escravidão e Razão Nacional. Em J. M. Carvalho, Pontos e Bordados: escritos de história e polítiac. Belo Horizonte: Editora da UFMG.

DOLHNIKOFF, M. (2005). O Pacto Imperial: origens do federalismo no Brasil. São Paulo: Globo.

FONSECA, S. C. (2005). A América como um Conceito: contribuição para o estudo da imprensa republicana fluminense e pernambucana entre 1829 e 1832. (F. A. Gusmão, \& C. d. Diplomática, Eds.) Cadernos do CHDD, IV(numéro especial).

GUERRA, F.-X., \& Lempériére, A. (1998). Los Espacios Públicos en Iberoamérica: ambiguidades y problemas. Siglos XVII-XIX. México: Fondo de Cultura Ecônomica-Centro Francês de Estudios Mexicanos y Centroamericanos.

HABERMAS, J. (2003). Mudança Estrutural da Esfera Pública: investigações quanto a uma categoria da sociedade burguesa. Rio de Janeiro: Tempo Brasileiro.

HUNT, L. (2009). A Invenção dos Direitos Humanos: uma história. São Paulo: Companhia das Letras.

Liberdade, A. d. (3).

Liberdade, A. d. (3).

NEVES, L. M. (2003). Corcundas e Constitucionais: a cultura política da Independência (1820-1822). Rio de Janeiro: REVAN, FAPERJ.

PEIXOTO, A. C. (2001). Liberais ou conservadores? Em L. Guimarães, \& M. Prado, O liberalismo no Brasil Imperial: origens, conceitos e prática. Rio de Janeiro: Editora REVAN.

POCOCK, J. G. (2003). Linguagens do Ideário Político. São Paulo: EDUSP.

PRADO, M. E. (2001). Ordem Liberal, Escravidão e Patriarcalismo: as ambiguidades do Império do Brasil. Em L. M. Guimarães, \& M. Costa, O Liberalismo no Brasil Imperial. Rio de Janeiro: REVAN.

REIS, A. F. (jun/dez. de 2015). Entre Smith e Quesnay: o debate econômico entre Plancher e Chapuis no Rio de Janeiro (1826). Revista Escritas, 7(2), 176-193.

REIS, A. F. (2016). “Anarquistas” e "servis” : uma análise dos projetos políticos do ano de1826 no Rio de Janeiro. Vitória: Dissertação (Mestrado em História) - Programa de PósGraduação em História Social das Relações Políticas - UFES.

ROCHA, A. P. (2000). Ideias antiescravistas da ilustração na sociedade escravista brasileira. Revista Brasileira de História, 20(39), 37-68.

SCHWARZ, R. (2001). As Ideias Fora do Lugar. São Paulo: Companhia das Letras e Penguim. 
SMITH, A. (1996). A Riqueza das Nações: investigações sobre sua natureza e suas casas. São Paulo: Nova Cultural.

YOUSSEF, A. E. (2011). Imprensa e Escravidão: política e tráfico negreiro no Império do Brasil. São Paulo. (Rio de Janeiro, 1822-1850). 2011. 300 f. Dissertação (Mestrado em História) - Universidade de São Paulo, São Paulo, 2011. 
